\title{
Activitat experimental per a treballar el model canvi químic a cicle superior de primària
}

\author{
Alícia Ferret Balanyà (alicia.ferret.balanya@gmail.com) \\ Begoña Oliveras (begona.oliveras@uab.cat) \\ Departament de Didàctica de les Matemàtiques i les Ciències. Universitat Autònoma de Barcelona
}

En aquest article es mostra el desenvolupament d'una activitat realitzada a 5è de primària per a treballar el model canvi químic a través d'un conjunt d'experiments. L'activitat pretén ajudar els alumnes a construir el model canvi químic a partir de fenòmens de la vida quotidiana. En l'activitat es fomenta la reflexió i la verbalització dels fenòmens observats.

Paraules clau: canvi químic, contextualitzar, treball experimental i model matèria

The paper presents the development of an activity carried out with 11-year-old students with the purpose of working the chemical change's model through a set of experiments. The activity aims to build the concept of chemical change in contrast with the concept of mixture through the phenomena of our everyday lives. The activity promotes self-reflection and the verbalization of the phenomena.

Key words: chemical change, science in context, practical work, matter model.

\section{INTRODUCCIÓ}

La finalitat de la ciència escolar és ajudar a l'alumnat a entendre els fenòmens que els envolten per a poder comprendre el món i actuar de manera raonada. Per fer-ho, cal entrar en contacte amb els fenòmens a estudiar, observar-los, manipular-los i discutir-los, fet que situa el treball experimental en el centre de l'activitat de les classes de ciències (Sanmartí, Márquez i García, 2002). El paper del treball experimental dins d'aquest procés és fonamental perquè permet que els alumnes intervinguin en el fenomen i, mitjançant el llenguatge, canviïn les seves formes de veure i representar el que perceben. (Estanya i Izquierdo, 2009).

\section{Un bon treball experimental}

El treball experimental no s'ha de limitar a manipular aparells i observar experiments, ja que amb aquests dos processos no assegurem que els alumnes comprenguin els fenòmens. L'alumnat ha de poder intervenir en els fenòmens i així poder elaborar explicacions sobre els mateixos. Per exemple, observar com reaccionen dues substàncies no vol dir comprendre què és un canvi químic. Per això és fonamental plantejar preguntes però també fomentar el diàleg i la discussió entre els alumnes per anar construint explicacions científiques que els permetin comprendre el món (Sanmartí, 2002).

Un bon treball experimental ha de partir de preguntes o problemes de la vida quotidiana, és a dir, hem de contextualitzar l'aprenentatge. Per això cal traslladar "fets i fenòmens del món" a l'aula per convertir-los en problemes rellevants des del punt de vista de la ciència. És important que a través dels experiments ajudem als alumnes a buscar semblances entre els fenòmens. Per exemple: cremar sucre, fer "desaparèixer una aspirina", obtenir substàncies de colors a partir d'altres incolores...., són observacions que poden conduir a plantejar-nos que tenen en comú i com s'expliquen aquests fenòmens. Aquests experiments podrien 
servir de punt de partida per a la construcció del model canvi químic (Sanmartí, Márquez i García, 2002). Entenent com a model una agrupació de conceptes, experiències, analogies, diferents tipus de llenguatges... que serveix per explicar un conjunt de fenòmens que succeeixen en el món (Sanmartí et al, 2003). No podem oblidar que l'objectiu de les ciències és que l'alumnat arribi a modelitzar (Izquierdo, 2012). Estaríem d'acord amb Viennot (2010) que la manera de presentar els experiments és molt important per ajudar a l'alumnat a formular explicacions científiques.. Viennot planteja la indagació com un mecanisme per ajudar a la comprensió dels fenòmens. Segons aquest autor és important remarcar els vincles entre els fenòmens i les lleis.

El llenguatge és l'eina per construir coneixement $\mathrm{i}$, en el cas de les ciències, també ho és la imaginació. Per arribar a construir el model canvi químic és necessari analitzar el fenomen des de la perspectiva macro (el que es pot observar a ull nu) i micro (el que passa per dins, el que s'ha d'imaginar) (Izquierdo, 2011). Totes dues perspectives són important i, per tant, s'ha d'anar passant d'una a l'altra per aconseguir una bona comprensió. Es tendeix a pensar que a primària no es pot treballar a nivell micro perquè implica utilitzar conceptes $\mathrm{i}$ procediments complexos. Això no és així ja que des de ben petits els alumnes poden imaginar com són les coses per dins i representar-les des del model partícula (Izquierdo, 2011).

Un bon treball experimental ha de finalitzar amb alguna activitat que ajudi als alumnes a organitzar, sintetitzar i reflexionar sobre el treball realitzat per tal de convertir la informació en coneixement. Això implica transformar les dades per a poder identificar regularitats, plantejar-se preguntes i imaginar explicacions (Sanmartí, 2002).

\section{El model canvi químic}

La química sempre s'ha considerat una disciplina molt complexa pels alumnes d'educació primària ja que s'associa a fórmules i a fenòmens perillosos. Tot i així, pensem que es pot ensenyar química des d'educació infantil.

L'objectiu d'ensenyar el model canvi químic a primària ha de ser el d'iniciar als alumnes en el món de la química a partir de fenòmens quotidians, per tal de treballar idees senzilles i útils que els ajudin a gestionar aquests fenòmens i, alhora, trencar amb els estereotips de que la química és una matèria complicada, que només es cosa de fórmules i de persones que treballen en el laboratori al marge de les coses interessants. És important que els alumnes puguin explicar fenòmens quotidians com una espelma que crema, la corrosió d'un metall, processos de neteja o simplement la respiració i la digestió, ja que són processos de la vida que no deixen de ser químics (Izquierdo 2006).

Les idees més importants del model canvi químic que hauríem d'ensenyar a primària són les diferències entre canvis químics i canvis físics, i les diferents interaccions (fortes 0 dèbils) entre les substàncies. És important que els alumnes s'adonin que no totes les substàncies interaccionen (n'hi ha que tenen més facilitat per fer-ho) i que en els canvis químics (forts) els materials interactuen $i$ canvien les seves propietats (Izquierdo, 2006).

Per a què els alumnes puguin construir el model canvi químic a partir de l'experimentació cal guiarlos a través de preguntes que no són habituals en el context quotidià com per exemple: "què tinc?", "què faig?", "què passa?" i "per què passa?". Fer pensar als alumnes sobre "què tinc" té com a objectiu que identifiquin totes les substàncies que intervenen i quines són les seves propietats (color, forma...). Per altra banda, que es preguntin "què faig" promou que es fixin en quins són els processos que duen a terme. La pregunta "què passa" ha de servir perquè els alumnes descriguin què observen, és a dir, els canvis que s'han produït (si les substàncies inicials canvien, desapareixen etc.). Per a respondre aquesta pregunta és fonamental que s'hagin contestat les dues primeres per tal de compara la descripció inicial amb el que s'observa després de que s'hagi produït el canvi. Per últim, el "per què passa" és una de les preguntes més difícils per ajudar a construir als alumnes però no impossible. Construir l'explicació del "per què" d'un canvi químic esdevé més fàcil si prèviament els alumnes han treballat el model matèria des d'una perspectiva "micro". Això implica que són capaços d'imaginar com es la matèria per "dins" i representar-la amb partícules. (Izquierdo, 2006).

Per últim, seria interessant preguntar als alumnes abans de fer l'experiment què creuen que passarà. La predicció és una habilitat molt important en les ciències que ajuda a activar els coneixements prèvies dels alumnes, fent més significatiu el seu aprenentatge.

\section{CARACTERÍSTIQUES DE L'ACTIVITAT DISSENYADA}

L'activitat es va dissenyar per a introduir el model canvi químic a primària. Es tractava d'un con- 
cepte nou per als alumnes que, tot i que apareix al currículum, no havien treballat a l'escola.

Per altra banda, els alumnes havien treballat prèviament les mescles i canvis físics $i$, per això, es va introduir el concepte de canvi químic a partir de la contraposició amb el concepte de mescla.

Els objectius proposats pretenien desenvolupar la capacitat de l'alumnat pel que fa a:

- Explicar de manera justificada la diferència entre una mescla i un canvi químic.

- Escriure un text justificatiu.

- Treballar en grup cooperativament.

L'activitat descrita va ser realitzada amb un grup de 22 alumnes d'una classe de 5 è de primària de l'escola Àgora de Sant Cugat del Vallès durant el curs 2012-2013 amb la presència de dos mestres. L'activitat va durar 2 hores.

\section{Punt de partida: l'activitat d'idees prèvies}

Per iniciar l'activitat es va demanar als alumnes que escrivissin individualment que era per a ells una mescla. Tot seguit se'ls va demanar que classifiquessin un llistat de matèries en funció de si eren mescles o no ho eren (llet amb cacau en pols, sucre, barreja d'aigua i oli, oxigen...). Després, se'ls va preguntar quin criteri havien seguit per fer la seva classificació. Finalment, es va demanar als alumnes que expliquessis si distingien diferents tipus de mescla.

La finalitat d'aquesta primera part de l'activitat era activar els coneixements previs dels alumnes en relació al concepte de mescla, ja que es volia construir el nou concepte de canvi químic partint dels conceptes que havien treballat anteriorment.

\section{Circuit de l'experiment}

L'activitat central de la sessió consistia en la realització de quatre proves experimentals:

1) "Què passa quan la fruita s'enfosqueix?". Consistia en comparar què li passa a un tros de poma acabada de tallar quan se li aplica el buit $i$ quan no se li aplica.

2) "No tallis la llimona sobre el marbre!". Consistia en tirar unes gotes de llimona sobre un tros de marbre.

3) "Aigua salada". Consistia en barrejar una cullerada de sal amb aigua.
4) "Aigua i oli". Consistia en barrejar una cullerada d'oli amb aigua.

Per fer-ho es va organitzar als alumnes en grups de quatre i se'ls va repartir el material dels quatre experiments. Els alumnes tenien un guió amb el procediment que havien de seguir per a cadascun dels experiments. Abans de començar es va llegir col-lectivament la introducció per explicar aspectes tècnics i aclarir dubtes, com per exemple, el funcionament d'un pot de buit [1]. Per tant, tot $\mathrm{i}$ que cada grup realitzava el seu experiment, tots anaven alhora de tal manera que la mestra podia gestionar el temps dedicat a cada part. Per a cada experiment, els alumnes havien d'omplir una taula amb les preguntes següents:

Què tinc a l'inici? Descriu les substàncies inicials.

- Què faig? Explica els passos que has seguit.

- Què passa? Explica què observes.

Per què passa? Quina creus que és l'explicació del que passa.

Què tinc al final? Descriu com són ara les substàncies.

Quadre 1. Preguntes que han de respondre els alumnes per a cada experiment.

A més, cada experiment anava acompanyat d'unes preguntes. Aquestes pretenien promoure la reflexió i la discussió entre els membres del grup per tal d'anar construint el model "canvi químic" en relació al concepte de mescla. Alguns exemples són:

Hi ha hagut algun canvi?

- Diries que el canvi és semblant al que s'ha produït a l'experiment de la roca?

- Quines característiques han canviat?

- Acabem de posar en contacte dues substàncies. Quines són? Encara hi són al final?

Quadre 2. Preguntes per reflexionar sobre els experiments.

\section{Treball posterior a la realització dels experiments}

Després de fer els quatre experiments es va demanar als alumnes que individualment els classifiquessin en dos grups i posessin un títol a cada grup. Aquest títol ens ajudaria a detectar els criteris de classificació que tenien els alumnes, i per tant, si havien identificat les característiques diferencials. 
Els experiments que acabem de fer es poden classificar en dos tipus. De quina manera els classificaries? Posa un títol a cada grup.

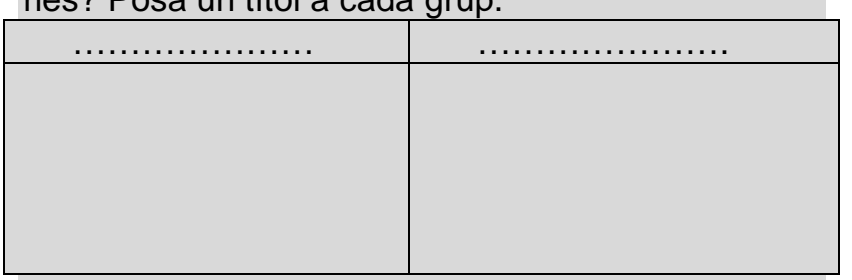

Explica perquè has posat aquests títols

Quadre 3. Activitat de classificació dels experiments.

A continuació, la mestra va iniciar una conversa amb el grup per a recollir les observacions i reflexions dels alumnes i, així, reconduir-los cap al model "canvi químic" a partir de les seves apreciacions. L'objectiu d'aquesta conversa era diferenciar "mescla" i "canvi químic" en relació a la intensitat d'interacció entre les substàncies (interacció forta o dèbil). Per a introduir el concepte d'interacció, es va utilitzar la idea de substàncies més o menys "amigues", és a dir, substàncies que tenen més 0 menys afinitat.

Tot seguit, es va demanar a l'alumnat que ampliés la classificació anterior a partir d'un llistat de fenòmens (cremar un tros de paper, moure una cadira, fer un pastís i congelar aigua) i els seus propis exemples.

A continuació, afegeix a la taula anterior els següents fenòmens:

- Cremar un tros de paper

- Moure una cadira

- Fer un pastís

- Congelar aigua

Per últim, afegeix-ne algun que se t'acudeixi.

Quadre 4. Exemples per ampliar la classificació.

Finalment, per tal de verbalitzar els coneixements adquirits, els alumnes van escriure amb les seves paraules la diferència entre mescla i canvi químic.

- "En la mescla s'ajunten dos productes per formar un altre. El canvi químic és quan un objecte es barreja amb un altre per canviar el producte."

- "Una mescla és una barreja entre dues o més coses i un canvi químic és una cosa més forta i com més amiga."

- "El canvi químic com el marbre i la llimona es transforma i la mescla no es transforma."
- "La mescla és molt dèbil (aigua i oli) i el canvi químic és molt fort (marbre i llimona)."

Quadre 5. Exemples de textos escrits pels alumnes.

\section{RESULTATS}

A l'inici de la sessió els alumnes no sabien explicar què era un canvi químic, probablement perquè no ho havien treballat prèviament. Pel que fa al concepte de mescla, la majoria el van definir com una barreja entre "coses, matèries o elements". Cap alumne va comentar que es tractés d'una barreja de substàncies pures, el que ens fa pensar que no han construït aquest concepte.

En l'experiment de la poma, tots els alumnes van explicar que amb la bomba havien tret l'aire. En canvi, per respondre a la pregunta "què passa?" van utilitzar diferents expressions: "la poma s'ha podrit", "la poma s'ha enfosquit" o bé "la poma s'ha tornat marró".

Cal destacar que els alumnes tenien dificultats per explicar per què passava el que observaven: "l'aire afecta la poma i l'enfosqueix", "la poma que ha connectat amb l'aire s'està podrint" o "totes les fruites que estan en contacte amb l'aire es podrei$x e n "$. Per tant, tot i que van identificar que és l'aire qui "posa" la poma marró, no van saber verbalitzar que es tractava d'una interacció entre l'aire i una cosa que té la poma (enzim de la cèl.lula vegetal).

No ens ha sorprès que utilitzessin la paraula "podrir" ja que en el context quotidià s'utilitza per a parlar de diferents fenòmens de manera indiscriminada. En aquest cas, es pot veure que els alumnes no saben què vol dir exactament ja que no es va produir una putrefacció. Potser seria interessant portar una poma podrida per veure que en la putrefacció hi ha una activitat biològica que no és present en l'enfosquiment de la poma.

Fixant-nos en l'experiment de la llimona i el marbre, alguns arguments que van utilitzar els alumnes per a justificar l'aparició de les bombolles $\mathrm{i}$ la taca blanca van ser: "perquè la llimona és molt àcida", "perquè el marbre xucla la gota de llimona" o bé "perquè la llimona és una substància molt forta". Cal destacar que la mestra va repetir l'experiment utilitzant àcid clorhídric (diluït al 10\%) perquè fos més espectacular i es veiessin més clarament les transformacions. Aquesta demostració va ajudar als alumnes a identificar la llimona com una substància que feia malbé el marbre, però 
no van entendre que es tractava d'una interacció entre dues substàncies. És a dir, no van entendre que la llimona fa malbé el marbre perquè aquesta roca està formada d'alguna cosa (carbonat càlcic) que interacciona amb la llimona. Per això, seria interessant comprovar que no totes les roques reaccionen amb la llimona i, així, els alumnes identificarien que es tracta d'una interacció entre dues substàncies. Es podria utilitzar la quarsita, una roca metamòrfica molt semblant al marbre però que no reacciona amb l'àcid clorhídric.

En aquest experiment també se'ls va preguntar quines característiques de la roca havien canviat. La majoria tornaven a referir-se a l'aparició de les taques blanques i només dos alumnes parlaven d'un canvi de color com una propietat que havia canviat.

Pel que fa a l'experiment de l'aigua i la sal, les idees mencionades pels alumnes per explicar què passava van ser: "la sal desapareix" o "no es veu la sal. En canvi, per explicar el perquè van utilitzar: "perquè la sal es desfà", "perquè es barreja" i "l'aigua absorbeix la sal".

Que els alumnes afirmin que la sal desapareix perquè es desfà, ens fa pensar que no han treballat el model matèria des d'una perspectiva "micro" i no s'han imaginat com és la matèria per dins. Com que no saben que la matèria no es destrueix, atribueixen a la química un component de màgia. Per això, tot l'alumnat creia que al final de l'experiment no es mantenien les substàncies inicials sinó que només quedava l'aigua.

Finalment, amb l'experiment de l'oli els alumnes van utilitzar els termes "flotar", "surar" i "quedar-se a dalt' per explicar què passava al barrejar aigua $\mathrm{i}$ oli. Al respondre a la pregunta "per què passa?" alguns alumnes van utilitzar arguments com: "perquè l'oli és més espès" $i$ "perquè l'oli és més líquid que l'aigua".

En canvi, la majoria no van saber justificar-ho: "perquè és impossible barrejar l'oli amb l'aigua", "perquè encara que barregis molt queda a dalt" $i$ "perquè l'oli ha surat", per la qual cosa podem inferir que els alumnes no dominaven els conceptes de densitat i de substàncies immiscibles.

Després de la pràctica es va demanar als alumnes si trobaven semblances entre els experiments, fent-los classificar els 4 experiments en dos grups. Tots els alumnes van agrupar l'experiment de la poma i el del marbre per una banda, i el de l'oli i el de la sal per l'altre, per tant, s'adonaven que pas- saven coses diferents. Però, quan se'ls va demanar que escriguessin un nom a cada una d'aquestes classificacions ens vam adonar que tenien dificultats per identificar el criteri de classificació.

Un nombre elevant d'alumnes va anomenar els grups amb els títols "canvi de color" (referint-se a la poma i marbre) i "barreges" (en el cas de l'aigua i l'oli, i l'aigua i sal). Uns altres, per altra banda, amb "canvi de color" i "canvi d'estat". Totes dues propostes es poden considerar una aproximació al concepte de canvi químic ja que "canvi de color" vol dir que ho associen a un canvi d'una propietat. Per últim, alguns van separar els fenòmens en "sòlids $\mathrm{i}$ líquids", una opció vàlida però que s'allunya de la comprensió del concepte de canvi químic. Per evitar aquesta confusió seria prudent fer un canvi en la proposta original $\mathrm{i}$ afegir un exemple de canvi químic on les substàncies que hi intervinguin estiguin en estat líquid.

La discussió posterior amb tota la classe sobre els experiments i la seva classificació va ajudar a comprendre el concepte de canvi químic. El fet que la mestra utilitzés el concepte "d'amistat" entre les substàncies va ajudar a comprendre la diferència entre una interacció feble (mescla i dissolució) i una interacció forta (canvi químic) (proposta feta per lzquierdo, 2008). Després de la discussió alguns alumnes van canviar els criteris de la classificació anterior per "més amigues i "menys amigues".

En els textos finals els alumnes van justificar quina era la diferència entre mescla i canvi químic utilitzant els termes $i$ arguments que havien anat sortint en la conversa amb tota la classe. Tenint en compte que l'alumnat estava poc acostumat a realitzar treball experimental i que era la primera vegada que feien una activitat d'aquest tipus, els avenços van ser importants.

\section{CONCLUSIONS}

L'experiència presentada és una activitat útil per a introduir el model "canvi químic" a cicle superior de primària. Com hem pogut veure a l'apartat anterior, els alumnes s'han aproximat al concepte de canvi químic al poder verbalitzar la diferència entre un canvi químic i una mescla.

En aquesta activitat hem apropat el concepte de canvi químic a partir de l'experimentació amb fenòmens de la vida quotidiana. L'objectiu era fer adonar a l'alumnat que processos tan senzills com l'enfosquiment d'una poma són química. 
L'experimentació directa amb el fenomen ha fomentat el diàleg entre els alumnes i els ha ajudat a construir el model "canvi químic", coherent amb la ciència i significatiu per a ells.

Tot i això, caldria acompanyar aquesta proposta amb altres activitats seguint el cicle d'aprenentatge per consolidar i interioritzar aquest nou coneixement. Un cop els alumnes han realitzat aquesta primera activitat, seria interessant analitzar els mateixos experiments des d'una perspectiva "micro", fent-los dibuixar com s'imaginen per dins el que tenen a l'inici i al final, i així anar construint el model canvi químic.

Al fer l'anàlisi de l'activitat hem detectat que els alumnes tenen dificultats per a definir criteris de classificació. Cal destacar que és important ajudar als alumnes a classificar, però encara ho és més que sàpiguen verbalitzar la diferència entre una categoria i una altra.

Per altra banda, també hem descobert que els ha estat difícil explicar el "perquè" dels fenòmens. Això pot ser perquè sovint les pràctiques de laboratori ofereixen poques oportunitats de discutir i analitzar els fenòmens pensant en termes del model. Una altra possible causa podria ser que l'alumnat no està acostumat a pensar una explicació del que succeeix més enllà del que observa. Estaríem d'acord amb Sanmartí (2002) que és molt important que l'alumne/a pugui comunicar, ja sigui oralment o per escrit, què ha après. El fet de verbalitzar-ho els ajuda a reestructurar el seu propi coneixement $i$ en conseqüència $a$ aprendre ciències.

En aquest cas, era molt difícil que els alumnes responguessin a la pregunta "per què passa" en termes d'interacció entre substàncies. Per això, va ser molt important la conversa posterior als experiments i la construcció conjunta del concepte d'interacció. El fet d'introduir el concepte "d'amistat" entre substàncies va ajudar-los a comprendre el concepte d'interacció i, conseqüentment, el model canvi químic.

A més, els alumnes van mostrar dificultats per construir la idea de canvi químic a partir dels fenò- mens que observaven. Creiem que aquest tipus d'activitats ajuden als nens i nenes a pensar inicialment sobre els "fets" i "fenòmens" que permeten acabar construint models.

Finalment, cal remarcar que l'alumnat en tot moment s'ha mostrat molt engrescat en l'activitat, tant en la part més experimental, com en la posterior discussió dels fenòmens observats.

\section{REFERÈNCIES}

ESTANYA, J. LL. I IZQUIERDO, M. (2009). Contribució del llenguatge al procés de modelització del canvi químic. Educació Química, 3, 11-19.

IZQUIERDO, M. (coord) (2011). Química a infantil i primaria. Una nova mirada. Barcelona: Graó

IZQUIERDO, M. (2006). ¿Puede enseñarse química en primaria? Guix. Elements d'Acció Educativa, 316-327, 28-36.

Sanmartí, N. (2002). Didáctica de las ciencias en la secundaria obligatoria. Barcelona: Síntesi

SANMARTÍ, N.; MÁRQUEZ, C. I GARCÍA, P. (2002). Los trabajos prácticos, punto de partida para aprender ciencias. Aula de Innovación Educativa, 113, 8-13.

SANMARTÍ, N. (comp) (2003). Aprendre ciències tot aprenent a escriure ciència. Barcelona: Ed. 62

VIENNOT, L (2011). Els molts reptes d'un ensenyament de les Ciències basat en la indagació: ens aportaran múltiples beneficis en l'aprenentatge? Ciències, 18, 22-36.

[1] Un pot de buit és un recipient que té un mecanisme per a treure l'aire que hi ha dins.

\section{AGRAIIMENTS}

Agraïm la participació de l'alumnat i mestres de cicle superior de l'escola Àgora de Sant Cugat del Vallès. 